\title{
Motivation and Learning Strategies Influencing Performance in an Aviation Course
}

\author{
Mary Niemczyk \\ Jon W. Ulrich \\ Arizona State University
}

\begin{abstract}
Collegiate aviation courses are very complex. The subject matter covered is oftentimes unfamiliar to students and unlike any topics they may have encountered during their high-school years. Since it is critical that students master the content, it is important to determine how they approach learning in these courses. Participants in this study completed a survey consisting of 81 motivation and learning strategies questions from the Motivated Strategies for Learning Questionnaire (MSLQ), and an open-ended question asking them to indicate the lowest course grade acceptable to them. Regression analyses of the MSLQ motivation and learning strategies found self-efficacy to be most significantly related to final course grade. Other analyses seem to indicate that learning strategies may need to be improved to promote more successful learning in these types of courses.
\end{abstract}

\section{INTRODUCTION}

Aviation courses are complex yet serve as the foundation for student success as aviation professionals. Oftentimes the subject matter covered is unfamiliar to the students and unlike any topics they may have encountered during their high school years. For many students, their first college semester may include courses such as meteorology, private pilot ground school, and air traffic control, among others. Since it is critical that students master the content, it is important to determine how students approach learning in these courses.

As instructors, we may assume that students enter college with some understanding of how to be engaged, strategic learners. Unfortunately, this is not an accurate assumption. Students do not necessarily develop effective learning strategies impulsively and findings in a recent study indicated that college students continue to struggle with learning during the final semesters of their academic programs (Rachal, Daigle, \& Rachal, 2007).

Many students enter college with little awareness of how to be an effective learner, and they tend to use the same learning strategies for all educational tasks. Research has indicated that most students have not had formal instruction in using various learning strategies and the strategies they use may have been developed through personal trial and error in completing homework assignments and studying for tests. They may judge the effectiveness of a strategy based on how well they performed. If they did as well as they expected, they may consider the strategy effective. If they didn't do as well as they expected, they may become frustrated and give up, instead of using a different learning strategy (Pintrich \& DeGroot, 1990). By contrast, research has found that strategic learners possess four essential characteristics: they critically assess tasks; define both shortterm and overall goals for studying; know alternative learning strategies that enable them to use the best strategy for the desired learning outcome; and, they make judgments about which strategies, or combinations of strategies, will offer them the greatest opportunity to achieve their goals (Hadwin, Winne, Stockley, Nesbit, \& Woszczyna, 2001).

\section{Self-regulation}

Students vary in their abilities to learn. Some seem to be strategic and are able to grasp concepts easily; others may struggle, while still others may exhibit characteristics of either from time to time. Researchers have come to attribute individual differences in learning to a students' ability to self-regulate (Zimmerman, 1989). Selfregulation focuses on what a student needs to know about him or herself in order to manage his or her efforts to learn. Although instructors need to know each student's strengths and limitations in learning, their goal should be to empower the student to become self-aware of their learning process.

Most students do not think much about how 
they learn new things. Teaching students about learning strategies helps them to become aware of how they process new information, to improve the strategies that they use, to learn new strategies, and develop systematic ways to approach studying and learning. Students need to become aware of the many and different ways that they can process information. They must also learn how to evaluate the effectiveness of different strategies for different learning situations (Weinstein \& Hume, 1998; Weinstein \& Meyer, 1991). If a student fails to understand some aspect of a lesson, he or she must possess the self-awareness and strategic knowledge to take corrective action. Even if it were possible for instructors to accommodate every student's limitations at any point during the course, their assistance could undermine a critical aspect of learning - a student's development of an ability to self-regulate (Zimmerman, 2002).

Previous research has found that selfregulated learning is an important aspect of student academic performance in the classroom. Students are self-regulated to the degree that they are metacognitively, motivationally, and behaviorally active participants in their own learning process. Self-regulated students initiate and direct their efforts to learn and do not overly rely on their teachers, parents, or peers. These students also utilize various learning strategies to achieve their desired academic goals; goals which they have established based on their selfefficacy regarding the concept or task. As a rule, self-regulated learning consists of three essential elements: commitment to academic goals, selfefficacy perceptions, and utilization of appropriate learning strategies (Zimmerman, 1989).

\section{Goal Orientation Theory}

Student academic goals are the underlying reasons or purposes for their learning behaviors. Essentially, goals represent the importance that a student assigns to a learning activity. Academic goals provide students with a means to not only define their successes and failures, but also how they may possibly react to the outcomes of their efforts (Urdan, 1997). Researchers on achievement motivation have found that different goal orientations elicit different motivational processes (Ames \& Archer, 1988).
Goals also provide the basis for the methodologies and learning strategies students may utilize in attempting to accomplish their desired learning outcomes (Kaplan \& Maehr, 2007).

\section{Mastery Goals}

Academic goals are most often described as either mastery or performance goals. Mastery goal orientation refers to a student's desire to develop a level of expertise, or outstanding ability (Ames, 1992; Dweck \& Leggett, 1988). Students possessing mastery goals are considered to be intrinsically motivated, and are primarily focused on mastering the course material. These students focus on in-depth learning, and understanding of the concepts. Because they value the learning process itself, mastery-oriented students often look for challenging assignments and put forth extra effort to learn the material. These students typically display active involvement in the course. They tend to participate more in class discussions and activities. Because these students enjoy learning, their questions to instructors are more likely to focus on enhancing their knowledge of the concepts rather than trying to determine whether they need to know the material just because it will appear on the next exam (Harackiewicz, Barron, \& Elliot, 1998).

Research has suggested that if students become interested in and enjoy the subject matter, they may spend more time and effort in studying. They will probably become more involved in the course activities, use higher-level effective learning strategies, and as a result, perform at an advanced level. These students' usually have high self-efficacy, and positive affect. They are typically persistent in their efforts, and prefer challenging tasks and activities (Ames, 1992; Dweck \& Leggett, 1988). Research has suggested that if a student is intrinsically motivated in one college course that may positively influence his or her performance not only in that course, but also in other courses (Harackiewicz, Barron, \& Elliot, 1998).

\section{Performance Goals}

In contrast, students with performance goals are considered to be extrinsically motivated. These students tend to focus on the 
outcome of their learning and are primarily interested in earning a good grade, or gaining social esteem (Dweck, 1986; Pintrich 1995). Learning the material is often seen as a means to an end rather than an end in itself. Performanceoriented students focus on managing the impression that others have of their ability. They attempt to create an impression of high ability and avoid creating an impression of low ability. These students are often found comparing themselves to their peers (Ames, 1992; Dweck, 1986).

A performance goal orientation has been found to be associated with the use of surface rather than higher-level learning strategies, and with negative affect in activities involving challenge or difficulty (Ames, 1992). Since they are mostly concerned with the reward that comes after they have learned the material, as opposed to actually mastering the subject matter, these students tend to use less effective learning strategies.

Interestingly, previous research has suggested that motivation is not a stable trait but is more situated, and contextual. Student motivation, therefore, probably varies as a function of subject matter domains and even by instructors, and classrooms (Linnenbrink \& Pintrich, 2002). In any case, students' own thoughts about their motivation and learning are critical in determining the level of effort contributed to attaining their desired outcomes.

\section{Self-Efficacy}

Although student goals provide direction and incentive for academic work, a second element of self-regulation affecting student achievement is the students' beliefs about his or her abilities. Belief in ones' ability to successfully perform a particular task is known as self-efficacy. Self-efficacy has been defined as an individuals' beliefs about their performance capabilities in a particular context or domain (Bandura, 1997).

Bandura (1986) stated that self-efficacy beliefs influence an individual's willingness to attempt a particular task, the level of effort he or she will spend, and his or her persistence in accomplishing the task. Self-efficacy is particularly important because of its two-fold effect on the other components of self- regulation. Not only does self-efficacy influence the type of goals students set for themselves but it also affects the amount of effort they invest in working toward these goals (Pintrich, 1995).

There has been a great deal of research focusing on self-efficacy in a variety of domains. Results of these studies seem to suggest that self-efficacy is positively related to many beneficial outcomes, such as choice, persistence, cognitive engagement, use of selfregulatory strategies, and actual achievement (Linnenbrink \& Pintrich 2002). Student behaviors can often be better predicted by their beliefs about their capabilities than by what they are actually capable of accomplishing. Results from previous research has shown that a student's beliefs help determine what they do with the knowledge and skills that they have (Pajares \& Miller, 1994). Typically, students with high self-efficacy are confident in their skills and abilities to do well and have been shown to participate more in learning activities. They exert more effort and persistence, and tend to achieve higher levels of academic success than students with low self-efficacy (Pintrich \& De Groot, 1990; Schunk, 1991). Even when experiencing difficulty, students with high selfefficacy tend to work longer and harder than do students with low self-efficacy. Students with low self-efficacy oftentimes show less determination and may attempt to avoid the learning situation altogether (Hagen \& Weinstein, 1995). Lack of self-efficacy has also been linked to high test-anxiety (Bandura, 1986). Students lacking confidence in their abilities may not perform as well on tests as students with high confidence levels.

\section{Learning Strategies}

A third element of self-regulation consists of student's learning strategies. Self-regulated learning strategies are the behaviors and actions students use to acquire concepts or skills. Students utilizing self-regulated learning strategies, such as organization and elaboration are actively engaged in their learning process. They are willing to use available academic resources; they may use the library, the Internet, and email their professors with questions. They also attend class, and complete course assignments (Rachal, Daigle, \& Rachal, 2007). 
These students also practice continuous awareness of their performance, and manage their time and study environments (Zimmerman, 1989; Zimmerman \& Martinez-Pons, 1988).

Students' use of self-regulated learning strategies depends not only on their knowledge of strategies but also on their academic goals and self-efficacy perceptions. Students with mastery goals tend to use deep processing strategies, such as organization and elaboration strategies, that will enhance their understanding of concepts. They attempt to integrate information and monitor their comprehension (Pintrich \& Garcia, 1991). Conversely, students with performance goals, tend to use strategies that promote only short-term and surface level processing, like memorizing and rehearsal (Graham \& Golan, 1991).

In much of the previous research on selfregulated learning, the focus has been on determining the foundational elements of the construct and the relationship between those elements. The results of these studies have indicated that self-regulatory processes are linked with content domains, and individuals learn how to apply these skills in a given learning or applied context (Zimmerman, 1998).

Determining the specific self-regulatory processes associated with successful learning in particular content domains is an important next step in this line of research. This study investigated the impact of self-regulatory processes on course grade in an aviation core course as determined by scores on the Motivated Strategies for Learning Questionnaire (MSLQ).

\section{Motivated Strategies for Learning Questionnaire (MSLQ)}

The MSLQ was developed to assess motivation and learning strategies utilized by students at the course level (Pintrich, Smith, Garcia \& McKeachie, 1991). The items on the assessment focus on the elements of selfregulation, and the interface between motivation and cognition (Duncan \& McKeachie, 2005). In total, there are 15 subscales, six focusing on motivational constructs, and nine focusing on learning constructs. The six motivation subscales are: Intrinsic Goal Orientation; Extrinsic Goal Orientation; Task Value; Control of Learning Beliefs; Self-Efficacy for Learning and Performance; and, Test Anxiety. The motivation section consists of 31 items. The nine learning strategy subscales are: Rehearsal; Elaboration; Organization; Critical Thinking; Metacognitive Self-Regulation; Time and Study Environment Management; Effort Regulation; Peer Learning; and Help Seeking. The learning strategy section consists of 50 items. Items are Likert-type, and range from 1 (not at all true of me) to 7 (very true of me) (see Appendix). Subscale scores are determined by calculating the mean score of the items on the scale. (Duncan \& McKeachie, 2005; Pintrich, et.al., 1991).

\section{METHODOLOGY}

\section{Participants}

All participants in this study were students in an aviation degree program at a major university. All students were enrolled in a required aviation meteorology course. Of the 108 participants, 87 were male and 21 were female. Seventy-three percent were freshman and $27 \%$ were sophomores. Students ranged in age from 18 years to 23 years, with an overall mean age of 19 .

\section{Materials}

The participants completed a two-part survey. The first section included demographic items as well as a selected-response question regarding the lowest grade that would be acceptable to them in this course. The second section consisted of the Motivated Strategies for Learning Questionnaire (MSLQ) (Duncan \& McKeachie, 2005; Pintrich, et. al., 1991).

\section{Procedures}

Students completed the survey during a class period. They were asked to sign an Authorization of Consent so that researchers could access their final course grades to compare to their survey responses. Participation in the study was voluntary.

\section{DATA ANALYSIS AND RESULTS}

\section{Lowest Grade Acceptable}

Participants were asked to indicate the lowest course grade that would be acceptable to them, A, B, C, D, or F. For each participant, the actual grade earned was then compared to the 
lowest grade acceptable. Table 1 provides a

to the actual grade earned.

comparison between the lowest grade acceptable

Table 1. Comparison of Lowest Grade Acceptable to Actual Grade Earned

\begin{tabular}{cc|rrrrr}
\hline $\begin{array}{c}\text { Lowest grade } \\
\text { acceptable }\end{array}$ & $\begin{array}{c}\text { Participants indicating } \\
\text { this as the lowest grade } \\
\text { acceptable }\end{array}$ & \multicolumn{7}{c}{ Actual grade earned by participants } \\
\hline & & A & B & C & D & F \\
A & $57(53 \%)$ & $23(40 \%)$ & $29(51 \%)$ & $5(9 \%)$ & -- & -- \\
B & $42(39 \%)$ & $8(20 \%)$ & $22(49 \%)$ & $11(30 \%)$ & $1(1 \%)$ & -- \\
C & $9(8 \%)$ & $2(20 \%)$ & $3(30 \%)$ & $3(30 \%)$ & $1(1 \%)$ & -- \\
\hline
\end{tabular}

$\mathrm{N}=108$.

All participants wanted to earn a grade of $\mathrm{C}$ or higher. Fifty-seven students indicated that an A was the lowest course grade acceptable to them, 42 students indicated a B was their lowest acceptable course grade, and nine students would accept a grade of C. In total, 48 students, or $44 \%$, earned the grade they indicated would be the lowest grade acceptable, 47 students, or $44 \%$, earned a grade lower than that which was acceptable, and 13 , or $12 \%$, of the students earned a grade higher than their lowest grade acceptable.

The range of final course grades was from A through D. Final course grades resulted in the following distribution: $\mathrm{A}=33(31 \%), \mathrm{B}=54$ (50\%), C = 19 (18\%), D = 2 (1\%). No students failed the course.

Three sets of analyses were conducted and results are organized accordingly. First, subscale mean scores were calculated. Then the motivation and learning strategy variables were separately analyzed to determine correlation with the final grade variable. Lastly, regression analyses were conducted. Description of the analyses and results follow.

\section{Results from MSLQ Assessment of Student Motivational Orientations and Learning Strategies}

Using the method developed by Pintrich et.al. (1991), the MSLQ sub-scale scores for each participant were constructed by taking the mean of the items that make up that scale. For example, intrinsic goal orientation has four items. An individual's score for intrinsic goal orientation was computed by summing the four items in the sub-scale and taking the average.
There were some negatively worded items and the ratings were reversed before an individual's score was computed. The statistics reported represent the positive wording of all the items. In general, a higher score of $4,5,6$, or 7 for a sub-scale mean score indicates that the student feels the items were a fairly good representation of their motivational orientation or learning strategies used in the course.

Table 2 displays the means and standard deviations for course grade and scores on the MSLQ sub-scales. Noteworthy sub-scale mean scores are discussed along with mean scores for individual items on these sub-scales.

The possible mean scores for the MSLQ sub-scales can range from one to seven. The selection of a one for an item on a sub-scale indicated that the student believed the item was not at all true of them, whereas a selection of seven indicated that the student believed the item was very true of them. The scores for all the individual items on the sub-scale were then averaged together to determine the mean score for the sub-scale.

\section{Motivation Strategy Sub-scale Results}

In response to the sub-scale items on the motivation scale, participants rated self-efficacy and control of learning beliefs fairly high, as indicated by the Self-Efficacy and Control of Learning Beliefs sub-scale mean scores (5.9 and 5.8 respectively). Participants also appear to not worry about course tests as indicated by a mean score of 3.6 on the Test Anxiety sub-scale. 
Table 2. Mean Scores and Standard Deviations on Course Grade and MSLQ Sub-scale Summaries

\begin{tabular}{llcc}
\hline & \multicolumn{1}{c}{ Variables } & Mean & $\begin{array}{c}\text { Standard } \\
\text { Deviation }\end{array}$ \\
\hline Course Grade & & & .75 \\
Motivation Scales & Intrinsic Goal Orientation & 3.0 & .93 \\
& Extrinsic Goal Orientation & 5.0 & 1.2 \\
& Task Value & 5.5 & 1.1 \\
& Control of Learning Beliefs & 5.5 & .83 \\
& Self-Efficacy for Learning and Performance & 5.8 & .88 \\
& Test Anxiety & 5.9 & 1.4 \\
Learning Strategy Scales & Rehearsal & 3.6 & 1.1 \\
& Elaboration & 5.0 & 1.1 \\
& Organization & 4.8 & 1.2 \\
& Critical Thinking & 4.1 & 1.1 \\
& Metacognition & 4.0 & .97 \\
& Time and Study Environment Management & 4.3 & 1.0 \\
& Effort Regulation & 4.7 & 1.2 \\
& Peer Learning & 5.1 & 1.4 \\
& Help Seeking & 3.5 & 1.2 \\
\hline
\end{tabular}

Note: Sub-scale mean scores can range from 1 to 7.

\section{Self-efficacy for learning and performance sub-scale results.}

There were eight items on the Self-efficacy for Learning and Performance sub-scale, with five items focusing on the students' judgment about his or her ability to accomplish the tasks for the course, and three items focusing on the students' expectation for success in the course.

Mean response scores for the five items focusing on the students' beliefs about being able to accomplish the tasks for the course were positive and ranged from 5.4 to 6.5 on the sevenpoint scale. These items asked students to rate their beliefs in their ability to understand both basic and complex course material, and their confidence in performing well on course assignments and tests.

Mean response scores for each of the three items focusing on the students' expectancy for success were also very positive and were over 5.8. These items asked students to rate their beliefs on being able to earn an excellent grade, and their beliefs in their overall ability to do well in the course.

\section{Control of learning beliefs sub-scale results.}

There were four items on the Control of Learning Beliefs sub-scale focusing on student's beliefs that their efforts to learn will result in positive outcomes. Mean response scores for the four items were positive and ranged from 5.0 to 6.2. These scores seem to indicate that students' took responsibility for their own learning of the course material.

\section{Test anxiety sub-scale results.}

There were five items on the Test Anxiety sub-scale, with three items focusing on worry or negative thoughts during test taking and two items focusing on physiological arousal aspects of anxiety, such as upset feelings, and rapid heart beat.

The mean response scores for the three items focusing on worry were approximately at the mid-point of the seven-point scale, ranging from 3.1 to 4.2. These mean scores seem to indicate that students were not worrying about the possibility of poor performance or even failure during test taking.

The mean response scores for the items focusing on the physiological aspects of anxiety were 3.3 and 3.5. These mid-range mean scores likewise seem to indicate that students were not upset or did not have uneasy feelings during test taking.

\section{Learning Strategy Sub-scale Results}

In response to the learning strategy items, participants rated effort regulation and rehearsal 
fairly high. The mean scores for the sub-scales were Effort Regulation, 5.1, Rehearsal 5.0.

\section{Effort Regulation sub-scale results.}

There were four items on the Effort Regulation subscale all focusing on the student's ability to control their effort and attention, and commitment to completion of learning tasks. Mean response scores for these items ranged from 4.4 to 5.5 .

\section{Rehearsal sub-scale results.}

There were four items on the Rehearsal scale all focusing on the use of memorization as a learning technique. Mean response scores for all four items were at the scale midpoint or higher and ranged from 4.3to 5.6.

\section{Analyses to Determine Relationship Among Motivational Orientations, Learning Strategies, and Course Grade}

The data were organized and analyzed via MS-Excel 2007. Separate tables for the Motivation and Learning strategies were generated. Given the nature of the data (i.e., selfreported Likert values), each strategy table was tested for possible autocorrelation amongst the strategies. Most of the strategies were found to be quite significantly correlated with each other $(p<0.001)$.

Consequently, each Motivation and Learning strategy variable was separately analyzed for correlation with the final grades. Prior to doing these separate analyses, the final letter grades were assigned an appropriate numerical value to represent grade points: $\mathrm{A}=4$, $\mathrm{B}=3, \mathrm{C}=2, \mathrm{D}=1$. Table 1 defines the distribution of actual grades earned.

Of the six Motivation Strategy factors and nine Learning Strategy factors, only three were found to be significantly correlated to final grade scores: Test Anxiety $(\mathrm{r}=-0.190, p<0.05)$, SelfEfficacy $(\mathrm{r}=0.256, p<0.01)$, and Effort Regulation $(\mathrm{r}=0.208, p<0.05)$. The autocorrelation analysis of Motivation Strategies demonstrated a significant negative correlation between Test Anxiety and Self-Efficacy ( $\mathrm{r}=$ $0.293, p<0.01$ ), so it would not be necessary to include both in a final model. A multiple regression against final grade scores was run with these two factors, and only Self-Efficacy retained significance $(p<0.01$, versus Test
Anxiety, $p>>0.05$ ). A final multiple regression with Self-Efficacy and Effort Regulation against final grade scores revealed that, again, only SelfEfficacy retained significance $(p<0.05$, versus Effort Regulation, $p>>0.05$ ).

There are two issues with the Self-Efficacy strategy. First, the assumption of normality is seemingly violated. However, this is most likely due to the dependent variable being discretely categorical (e.g., A, B, C, etc.). Normality would likely be maintained if there was a greater level of fidelity in the results (e.g., A, A-, B+, etc., or $96 \%, 95 \%, 93 \%, 87 \%$, etc.). The second issue is with the residuals not being fully random, but this is again most likely attributable to the nature of the output variable values.

\section{DISCUSSION}

The purpose of this study was to determine the relationship among student self-reports of their motivation and learning strategy use to their academic performance in an aviation course as indicated by course grade. Overall, the results appear to indicate that these students felt very confident in their abilities to do well in the course. They reported having high self-efficacy and low test-anxiety. They believed that their efforts would result in their desired course outcome, and were committed to reaching their academic goals. Forty-four percent of the students earned the grade they indicated was the lowest grade acceptable to them, while another $44 \%$ earned a poorer grade than the lowest grade acceptable to them. Twelve percent of the students earned a grade higher than their lowest grade acceptable.

In terms of motivation strategies, selfefficacy is positively related to course grade. Students with high self-efficacy are confident in their ability to succeed in accomplishing learning activities. They tend to accept challenging tasks, and exhibit perseverance and determination in achieving their learning goals (Miller, Behrens, Greene, \& Newman, 1993).

Self-efficacy beliefs also influence the amount of stress and anxiety students experience as they attempt to complete a task. In the current study, students reported high self-efficacy beliefs. It is, therefore, not surprising that they also indicated they had low-test anxiety. 
Individuals with a strong sense of competence approach tasks willingly and perceive them to be opportunities for learning. By contrast, individuals with low self-efficacy beliefs may feel that learning situations are tougher than they really are. This type of perspective oftentimes promotes stress, anxiety, and apprehension. These feelings may then hamper a students' ability to problem solve and think critically (Pajares, 1997).

Self-efficacy has been also been associated with increased levels of persistence in accomplishing tasks. Previous research has found a positive relationship between selfefficacy and student effort, both mental and physical (Zimmerman, 2000). Students in the current investigation believed that their efforts to study would make a difference in both their learning and in their ability to achieve their desired course goals. They also reported that they were committed to completing their study goals, even when faced with difficulties or distractions.

The students in this study indicated that they were committed to achieving their learning goals, however, many (44\%) students earned a grade lower than the lowest grade acceptable to them. Students that are unfamiliar with a content domain may not know how to think within that domain. In this study, $73 \%$ of participants were freshman. Pintrich (1995) suggests that in order for students to become successful learners, instructors need to assist students in becoming aware of how to think, learn, and reason within the particular discipline.

Results from previous research have indicated that use of various learning strategies may be conditional and contextualized. Students, therefore, need to understand the situations when certain learning strategies may be more or less effective (Pintrich \& Garcia, 1994). Knowing about and using learning strategies is a major factor for discriminating between low achieving students and those who experience success (Alexander \& Judy, 1988; Pintrich \& DeGroot, 1990).

Many students indicated that they utilized the learning strategy of rehearsal; however, this factor was not statistically significant. Rehearsal strategies enable students to store information in working, or short-term, memory. Without the use of active, higher-level learning strategies, this information may never be transferred to long-term memory. For learning to be more effective and efficient, students need to actively work with the material utilizing elaboration strategies, or reorganizing the material in such a way that the new information is able to be stored in the student's long-term memory. Use of these types of strategies will allow for a stronger foundation of knowledge and enable students to recall information more readily (Niemczyk, 2008; Niemczyk \& Savenye, 2005; Weinstein \& Meyer, 1991).

Motivation and learning strategies essential to success within a particular domain can be developed through active and constructive interactions with the concepts of the discipline. Through collaborative interactions with instructors and peers, students can develop the strategies critical to success (Boekaerts \& Cascallar, 2006). As a means of promoting student success, faculty are encouraged to become more familiar with how to explicitly teach basic and content-specific learning strategies (Rachal, Daigle, \& Rachal, 2007).

\section{CONCLUSION}

The results of this study highlight the motivation and learning strategies most related to course grade in an aviation course. This study not only provides information on students' learning goals and their use of self-regulated learning strategies, but it also gives insight to how collegiate aviation students view learning and the methodologies they use to study. Assisting students in developing and using effective and efficient motivation and learning strategies is critical since it will enable them to achieve their current learning goals, as well as help them become successful lifelong learners. 


\section{REFERENCES}

Alexander, P. A., \& Judy, J. E. (1988). The interaction of domain-specific and strategic knowledge in academic performance. Review of Educational Research, 58, 375-404.

Ames, C. (1992). Classrooms: Goals, structures, and student motivation. Journal of Educational Psychology, 84(3), 261-271.

Ames, C., \& Archer, J. (1988). Achievement goals in the classroom: Students' learning strategies and motivation processes. Journal of Educational Psychology, 80(3), 260-267.

Bandura, A. (1986). Social foundations of thought and action: A social cognitive theory. Englewood Cliffs, NJ: Prentice Hall.

Bandura, A. (1997). Self-Efficacy: The exercise of control. Freeman: New York.

Boekarts, M., \& Cascallar, E. (2006). How far have we moved toward the integration of theory and practice in self-regulation? Educational Psychology Review, 18, 199-210.

Duncan, T., \& McKeachie, W. (2005). The making of the motivated strategies for learning questionnaire. Educational Psychologist, 40(2), 117-128.

Dweck, C. (1986). Motivational processes affecting learning. American Psychologist, 41(10), 1040-1048.

Dweck, C. S., \& Leggett, E. L. (1988). A social-cognitive approach to motivation and personality. Psychological Review, 95(2), 256-273.

Graham, S., \& Golan, S. (1991). Motivational influences on cognition: Task involvement, ego involvement, and depth of information processing. Journal of Educational Psychology, 83(2), 187194.

Hadwin, A., Winne, P., Stockley, D., Nesbit, J., \& Woszczyna C. (2001). Context moderates students' self-reports about how they study. Journal of Educational Psychology, 93(3), 477-487.

Hagen, A., \& Weinstein, C. (1995). Achievement goals, self-regulated learning, and the role of classroom context. In P. Pintrich (Ed.), Understanding Self-regulated Learning (pp. 43-55). San Francisco: Jossey-Bass Publishers.

Harackiewicz, J. M., Barron, K. E., \& Elliot, A. J. (1998). Rethinking achievement goals: When are they adaptive for college students and why? Educational Psychologist, 33(1), 1-21.

Linnenbrink, E. A., \& Pintrich, P. R. (2002). Motivation as an enabler for academic success. School Psychology Review, 31(3), 313-327.

Miller, R. B., Behrens, J. T., Greene, B. A., \& Newman. D. (1993). Goals and perceived ability: Impact on student valuing, self-regulation, and persistence. Contemporary Educational Psychology, 18(1), 2-14.

Niemczyk, M. (2008). Student approaches to learning in aviation contexts. Journal of Aviation / Aerospace Education and Research, 18(1), 19-28.

Niemczyk, M., \& Savenye, W. (2005). Self-regulation in a computer literacy course. Academic Exchange Quarterly, 9(4), 55-61.

Pajares, F. (1997). Current directions in self-efficacy research. In M. L. Maehr \& P. R. Pintrich (Eds.), Advances in motivation and achievement (pp. 99-141). Greenwich, CT: JAI Press.

Pajares, F., \& Miller, D. M. (1994). Role of self-efficacy and self-concept beliefs in mathematical problem solving: a path analysis. Journal of Educational Psychology, 86(2), 193-203. 
Pintrich, P. R. (1995). Understanding self-regulated learning. In P. Pintrich (Ed.), Understanding Selfregulated Learning (pp. 3-12). San Francisco: Jossey-Bass Publishers.

Pintrich, P. R., \& DeGroot, E. V. (1990). Motivational and self-regulated learning components of classroom academic performance. Journal of Educational Psychology, 82, 33-40.

Pintrich, P., \& Garcia, T. (1991). Students goal orientation and self-regulation in the college classroom. In M. Maehr \& P. Pintrich (Vol. Eds.), Advances in Motivation and Achievement: Vol. 7 (pp. 371-402). Greenwich, CT: JAI Press, Inc.

Pintrich, P., \& Garcia, T. (1994). Self-regulated learning in college students: Knowledge, strategies, and motivation. In P. R. Pintrich, D. R. Brown, C. E. Weinstein (Eds.), Students motivation, cognition, and learning: Essays in honor of Wilbert J. McKeachie, (pp.113-133).

Pintrich, P. R., Smith, D. A., Garcia, T., \& McKeachie, W. J. (1991). A manual for the use of the motivated strategies for learning questionnaire (MSLQ). (Tech. Rep. No. 91-B-004). The Regents of The University of Michigan.

Rachal, K., Daigle, S., \& Rachal, W. (2007). Learning problems reported by college students: Are they using learning strategies? Journal of Instructional Psychology, 34(4), 191-199.

Schunk, D. H. (1991). Self-efficacy and academic motivation. Educational Psychologist, 26(3/4), 207231.

Urdan, T. C., (1997). Achievement goal theory. In M. L. Maehr \& P. R. Pintrich (Eds.), Advances in motivation and achievement (pp. 99-141). Greenwich, CT: JAI Press.

Weinstein, C.E., \& Hume, L. (1998). Study strategies for lifelong learning. Washington, DC.: American Psychological Association.

Weinstein, C. E., \& Meyer. D. K. (1991). Cognitive learning strategies and college teaching. New directions for teaching and learning, 45, 15-26.

Zimmerman, B. J. (1989). A social cognitive view of self-regulated academic learning. Journal of Educational Psychology, 81(3), 329-339.

Zimmerman, B. J. (1998). Academic studying and the development of personal skill: A self-regulatory perspective. Educational Psychologist, 33(2/3), 73-86.

Zimmerman, B.J. (2000). Self-efficacy: An essential motive to learn. Contemporary Educational Psychology, 25, 82-91.

Zimmerman, B. J. (2002). Becoming a self-regulated learner: An overview. Theory Into Practice, 41(2), 64-70.

Zimmerman, B. J., \& Martinez-Pons, M. (1988). Construct validation of a strategy model of student selfregulated learning. Journal of Educational Psychology, 80(3), 284-290. 


\section{APPENDIX}

\section{Motivation Strategies}

1. In a class like this, I prefer course material that really challenges me so I can learn new things.

2. If I study in appropriate ways, then I will be able to learn the material in this course.

3. When I take a test, I think about how poorly I am doing compared with other students.

4. I think I will be able to use what I learn in this course in other courses.

5. I believe I will receive an excellent grade in this class.

6. I'm certain I can understand the most difficult material presented in the readings for this course.

7. Getting a good grade in this class is the most satisfying thing for me right now.

8. When I take a test, I think about items on other parts of the test I can't answer.

9. It is my own fault if I don't learn the material in this course.

10. It is important for me to learn the course material in this class.

11. The most important thing for me right now is improving my overall grade point average, so my main concern in this class is getting a good grade.

12. I'm confident I can learn the basic concepts taught in this course.

13. If I can, I want to get better grades in this class than most of the other students.

14. When I take tests I think of the consequences of failing.

15. I'm confident I can understand the most complex material presented by the instructor in this course.

16. In a class like this, I prefer course material that arouses my curiosity, even if it is difficult to learn.

17. I am very interested in the content area of this course.

18. If I try hard enough, then I will understand the course material.

19. I have an uneasy, upset feeling when I take an exam.

20. I'm confident I can do an excellent job on the assignments and tests in this course.

21. I expect to do well in this class.

22. The most satisfying thing for me in this course is trying to understand the content as thoroughly as possible.

23. I think the course material in this class is useful for me to learn.

24. When I have the opportunity in this class, I choose course assignments that I can learn from even if they don't guarantee a good grade.

25. If I don't understand the course material, it is because I didn't try hard enough. 
26. I like the subject matter of this course.

27. Understanding the subject matter of this course is very important to me.

28. I feel my heart beating fast when I take an exam.

29. I'm certain I can master the skills being taught in this class.

30. I want to do well in this class because it is important to show my ability to my family, friends, employer, or others.

31. Considering the difficulty of this course, the teacher, and my skills, I think I will do well in this class.

\section{Learning Strategies}

32. When I study the readings for this course, I outline the material to help me organize my thoughts.

33. During class time I often miss important points because I'm thinking of other things.

34. When studying for this course, I often try to explain the material to a classmate or friend.

35. I usually study in a place where I can concentrate on my course work.

36. When reading for this course, I make up questions to help focus my reading.

37. I often feel so lazy or bored when I study for this class that I quit before I finish what I planned to do.

38. I often find myself questioning things I hear or read in this course to decide if I find them convincing.

39. When I study for this class, I practice saying the material over and over.

40. Even if I have trouble learning the material in this class, I try to do the work on my own, without help from anyone.

41. When I become confused about something I'm reading for this class, I go back and try to figure it out.

42. When I study for this course, I go through the readings and my class notes and try to find the most important ideas.

43. I make good use of my study time for this course.

44. If course readings are difficult to understand, I change the way I read the material.

45. I try to work with other students from this class to complete the course assignments.

46. When studying for this class, I read my class notes and the course readings over and over again.

47. When a theory, interpretation, or conclusion is presented in class or in the readings, I try to decide if there is good supporting evidence.

48. I work hard to do well in this class even if I don't like what we are doing.

49. I make simple charts, diagrams, or tables to help me organize course material. 
50. When studying for this course, I often set aside time to discuss course material with a group of students from the class.

51. I treat the course material as a starting point and try to develop my own ideas about it.

52. I find it hard to stick to a study schedule.

53. When I study for this class, I pull together information from different sources, such as lectures, readings, and discussions.

54. Before I study new course material thoroughly, I often skim it to see how it is organized.

55. I ask myself questions to make sure I understand the material I have been studying in this class.

56. I try to change the way I study in order to fit the course requirements and the instructor's teaching style.

57. I often find that I have been reading for this class but don't know what it was all about.

58. I ask the instructor to clarify concepts I don’t understand well.

59. I memorize key words to remind me of important concepts in this class.

60. When course work is difficult, I either give up or only study the easy parts.

61. I try to think through a topic and decide what I am supposed to learn from it rather than just reading it over when studying for this course.

62. I try to relate ideas in this subject to those in other courses whenever possible.

63. When I study for this course, I go over my class notes and make an outline of important concepts.

64. When reading for this class, I try to relate the material to what I already know.

65. I have a regular place set aside for studying.

66. I try to play around with ideas of my own related to what I am learning in this course.

67. When I study for this course, I write brief summaries of the main ideas from the readings and my class notes.

68. When I can't understand the material in this course, I ask another student in this class for help.

69. I try to understand the material in this class by making connections between the readings and concepts from lectures.

70. I make sure that I keep up with the weekly readings and assignments for this course.

71. Whenever I read or hear an assertion or conclusion in this class, I think about possible alternatives.

72. I make lists of important terms for this course and memorize the lists.

73. I attend this class regularly.

74. Even when course materials are dull and uninteresting, I manage to keep working until I finish. 
75. I try to identify students in this class whom I can ask for help if necessary.

76. When studying for this course I try to determine which concepts I don't understand well.

77. I often find that I don't spend very much time on this course because of other activities.

78. When I study for this class, I set goals for myself in order to direct my activities in each study period.

79. If I get confused taking notes in class, I make sure I sort it out afterwards.

80. I rarely find time to review my notes or readings before and exam.

81. I try to apply ideas from course readings in other class activities such as lecture and discussion. 